\title{
İç Boşluklu Akustik Metamalzemelerin Homojenizasyonu ve İletim Kayıplarının Transfer Matris Metodu ile Belirlenmesi
}

\author{
Homogenization of In-line Cavity Based Acoustic \\ Metamaterials and The Determination of Transmission \\ Losses via Transfer Matrix Method
}

\author{
Abdullah Seçgin ${ }^{*}(\mathbb{0}$, Tuba Baygün 1 (1) \\ ${ }^{1}$ Dokuz Eylül Üniversitesi Mühendislik Fakültesi Makine Mühendisliği Bölümü, İzmir, TÜRKIYYE \\ Sorumlu Yazar / Corresponding Author*: abdullah.secgin@deu.edu.tr \\ Geliş Tarihi / Received: 26.10 .2018 \\ DOI:10.21205/deufmd.2019216211 \\ Kabul Tarihi / Accepted: 27.12.2018 \\ Arastırma Makalesi/Research Article
}

Atıf șekli/How to cite: SEÇGIN, A., BAYGÜN, T. (2019). İç Boşluklu Akustik Metamalzemelerin Homojenizasyonu ve İletim Kayıplarının Transfer Matris Metodu ile Belirlenmesi. DEUFMD, 21(62), 449-459.

Öz

Bu çalışmada, yüksek ses iletim kaybına (TL) sahip yalıtım malzemesi olarak kullanılmak üzere küresel iç boşluklu akustik metahücrelerden oluşan çeșitli akustik metamalzemeler tasarlanmıştır. $\mathrm{Bu}$ malzemelerin iletim kayıpları vizko-termal kayıplar ihmal edilerek transfer matris metodu (TMM) ile belirlenmiştir. Metamalzemelerin etkin empedans, kırllma indisi, yoğunluk ve sıkıştırlabilirlik (tersi Bulk modülü) gibi etkin ortam parametreleri etkin ortam homojenizasyonu ile elde edilmiștir. Metamalzemeleri olușturan metahücrelerin sayısı, geometrik büyüklükleri, dizilim periyodikliği gibi topolojik unsurların iletim kaybı üzerindeki etkisi incelenerek metamalzemelerin frekans bölgelerine göre performansları ortaya konmuștur. Sunulan yöntemin doğruluğu sonlu elemanlar metodu (SEM) ile yapılan bir karşılaştırma ile gösterilmiştir. Çalışma ile TMM ile akustik metamalzeme tasarımı ve analizleri ve etkin ortam homojenizasyonu ile etkin parametrelerin elde edilmesi gibi konular detaylı bir șekilde sunulmuștur.

Anahtar Kelimeler: Akustik metamalzeme, transfer matris yöntemi, etkin ortam teorisi, etkin parametreler

\section{Abstract}

In this study, a variety of acoustic metamaterials consisting of in-line cavity based metacells are designed, for use as insulation material with high sound transmission loss. The transmission losses of these materials were determined by the transfer matrix method (TMM) with neglecting viscothermal losses. Effective medium parameters such as effective impedance, refractive index, density and compressibility (inverse of Bulk modulus) of the metamaterials are obtained by effective medium homogenization. The effects of number of metacells, geometric size and the periodicity of the elements on the transmission loss (TL) are examined, and the performance of the metamaterials regarding frequency domain is discussed. The accuracy of the present method is demonstrated by finite element method. In the study, the topological issues such as acoustic metamaterial design and analysis and obtaining effective parameters with effective medium homogenization using the TMM, are presented in detail.

Keywords: Acoustic metamaterials, transfer matrix method, effective medium theory, effective parameters 


\section{Giriş}

Ses ve gürültü kontrolü otomotiv, havacılık, endüstriyel makinalar, beyaz eșya, ev aletleri sanayi, havalandırma sistemleri, inşaat ve yapı sektörü gibi pek çok alanda önemli bir yere sahiptir. İstenmeyen ses olarak tanımlanan gürültü, ürünlerin ve sistemlerin enerji verimliliğini, konfor ve ömrünü etkileyen önemli bir unsurdur. Yapısal veya hava kaynaklı olarak sınıflandırılan gürültünün azaltımı veya iletimi çeşitli tekniklerle kontrol edilebilmektedir. $\mathrm{Bu}$ kontrol genellikle aktif, pasif veya adaptif yalıtım ile gerçekleștirilir. Aktif yalıtım gürültünün kaynağında çözümü öngörürken, pasif yalıtım genellikle kaynak ile alıcı arasına yerleștirilen bir yalıtım/iletim malzemesi ile sağlanır. Adaptif yalıtım ise genellikle gürültü ile alıcı arasında yayınan ses dalgasını söndürmek (nötralize etmek) üzere elektriksel olarak ters fazlı bir sesin üretilmesi ile gerçekleştirilir. Yalıtım malzemelerinin performansı ses yutma (absorblama) katsayısı, iletim kaybı, eklenti kaybı ve gürültü azaltımı gibi frekansa bağlı çeşitli akustik performans parametreleri ile belirlenir.

Metamalzemeler, genellikle periyodik, altdalgaboylu hacimsel hücrelerden/ atomlardan/birimlerden oluşan, egzotik özellikli, ancak sürekli bir malzeme olarak davranan yapay yapılardır. "meta" kelimesi, Yunanca "öte", "ötesi" anlamına gelir. Bu bağlamda metamalzeme, bilinen geleneksel malzemelerin sahip olduğu fiziksel (mekanik, elektromanyetik vb.) özelliklerin ötesinde sıradışı (egzotik) davranış gösteren malzeme olarak tanımlanır. Sıradıșı özellikler, malzemelerin negatif etkin (efektif) yoğunluğa ve/veya negatif etkin Bulk modülüne (negatif sıkıștırılabilirliğin tersi) sahip olması anlamında kullanılmaktadır. Metamalzemeler kendini oluşturan yapının ana malzemesinin kimyasal özelliklerinin ötesinde, olușturulan yapının fiziksel ve geometrik özellikleri ile karakterize edilir.

İsmi konulmamış olmasına rağmen metamalzemeler üzerine ilk kuramsal çalışma Victor Veselago tarafindan 1967 'de yapılmıștır [1]. Veselago, bir elektromanyetik ortamda faz ve grup hızlarının birbirleri ile zıt yönlü olabileceğini ifade etmiştir. Bu çalışma, faz hızının negatif olmasını, dolayısıyla kırılma indisinin de negatif olacağını göstermesi sebebiyle metamalzemelerin bilimsel araștırmalar ve endüstriyel uygulamalar için çok büyük bir potansiyele sahip olduğunu göstermiştir. Akustik metamalzemelerin teorik temelleri, elektromanyetik metamalzemeler hakkındaki mevcut bilgiler üzerinden akustik, mekanik ve elektriksel niceliklerle kurulan benzetimlere (analojilere) dayanmaktadır. Elektromanyetik metamalzemeler üzerinde çalışılmış olan süper odaklama, akustik görünmezlik gibi bazı uygulamalar akustik metamalzemeler için de gerçekleștirilmiștir [27].

Akustik metamalzemeler üzerine son 15 yılda çeşitli amaçlar doğrultusunda çok fazla sayıda bilimsel araştırma mevcuttur. Akustik metamalzemeler genellikle uygulama amaçlarına, negatiflik özelliklerine ve hücresel özelliklerine göre üç șekilde sinıflandırılırlar. Ancak son iki sınıflandırma daha teknik bir sınıflandırmadır ve Tablo 1'de verilmiștir. Burada akustik metamalzemelerin teorik ve deneysel olarak geliştirilmesine ilișkin bazı temel çalışmalardan, hücresel özelliklerine göre sinıflayarak bahsetmek faydalı olacaktır.

Tablo 1. Akustik metamalzemelerin siniflandırılması.

\begin{tabular}{lllr}
\hline $\begin{array}{l}\text { Negatiflik } \\
\text { Özelliğine Göre }\end{array}$ & $\begin{array}{l}\text { Hücresel } \\
\text { Özelliklerine Göre }\end{array}$ \\
\hline Tek negatiflik (TNG) & Fononik kristal & \\
Çift negatiflik (ÇNG) & $\begin{array}{l}\text { Yerel rezonant } \\
\text { tabanlı }\end{array}$ & sonik \\
Yaklaşık sıfır (YSF) & $\begin{array}{l}\text { Yerel akustik boşluk } \\
\text { tabanlı }\end{array}$ & \\
& Membran tipi & \\
& Hibrit & \\
\hline
\end{tabular}

Zhang ve Liu [8] iki boyutlu fononik kristallerde akustik dalgaların da elektromanyetik dalgalar gibi negatif kırılma indisine sahip olabileceğini göstermişlerdir. Çalışmada bir mikro süper lens tasarlayarak elektromanyetik dalgaların fotonik kristallerde gösterdiği süper odaklama davranışını akustik dalgalar için de ortaya koymuşlardır. Liu ve ark. [9] ise düzensiz, kompozit (birden fazla ana malzeme içeren) fononik kristaller ile yerel rezonant davranıș yaratmışlardır. $\mathrm{Bu}$ kompozit yapı negatif elastisite modülüne sahip olarak yerel meta davranış sergilemiştir. Zhao ve ark. [10] fononik kristallerin sergilediği Bragg bant genişliğini, etkin homojen ortam ile katı cisim rezonansları arasındaki etkileşim ile artırmışlardır. 
DEU FMD 21(62), 449-459, 2019

Fang ve ark. [11] Nature Materials dergisinde yayınladıkları makalelerinde Helmholtz rezonatör serilerinden oluşan negatif sıkıştırılabilirliğe (tersi Bulk modülü) sahip bir ultrasonik metamalzeme tasarlamışlar, ve bu malzeme ile faz ve grup hızının birbirleri ile zit yönde olabileceğini göstermişleridir. Hu ve ark. [12] ise akışkan içerisinde bulunan bir Helmholtz rezonatörünün etkin ortam parametrelerini analitik olarak elde ederek, Fang ve ark. [11]' nın bahsedilen bulgularını desteklemişlerdir. Lee ve ark. [13] bir boru iletim hattında kenar deliklere sahip farklı bir metamalzeme geliştirerek negatif sıkıştırılabilirlik yaratmışlardır. Bu malzeme ile $450 \mathrm{~Hz}$ 'in altında iletimi kestiklerini analitik ve deneysel çalışmalarla göstermişlerdir.

Lee ve ark. [14] bu kez aynı boru iletim hattına çok ince membranlar yerleştirerek, membranların rezonans frekanslarında negatif yoğunluğa sahip bir metamalzeme geliştirmişlerdir. Yang ve ark.[15] çok ince membranlar üzerine yerleştirdikleri küçük kütlelerle istenilen frekanslara ayarlanabilen ve böylelikle negatif etkin yoğunluk özelliği gösteren bir bașka metamalzeme tasarlamışlar ve deneysel olarak çalışmalarını doğrulamışlardır. Yao ve ark. [16], negatif yoğunluk özelliğinin çok sayıda küçük kütle ve yay sistemlerinden oluşan osilatörlerle sağlanabildiğini deneysel olarak göstermişlerdir.

Bant boşluklarının yerel rezonans ve Bragg saçılımının kombine edilerek büyütülebildiği, etkisinin artırılabildiği hibrit metamalzemeler üzerine son dönemlerde çeşitli çalışmalar yapılmıștır [17-19]. Bunlardan Chen ve Wang [18] Bragg saçılımı ve yerel rezonansların bağlaşık etkisinin dalga filtreleme özelliğini artırdığını sayısal simülasyonlarla göstermişlerdir. Elde edilen bant boşluklarının metamalzemenin topolojik yapısının değiştirilmesi ile ayarlayabildiğinin gözlenmesi bu konuda oldukça önemli bir bulgudur. Bununla birlikte yine aynı anda sıfır ve/veya negatif kütle ve/veya negatif elastisite özelliği gösteren metamalzemeler tasarlanmıștır [1923].

Literatürde sözü edilen çalıșmalara ek olarak, bu çalışmada, bir panel yalıtım malzemesi olarak yüksek ses iletim kaybına sahip küresel iç boşluklu (KIB) akustik metahücrelerden oluşan çeşitli akustik metamalzemeler tasarlanmış ve bu malzemelerin ses iletim kayıpları transfer matris metodu (TMM) ile belirlenmiștir. Çalışmada vizko-termal etkiler ihmal edilerek, küresel iç boşluklu bu malzemelerin negatif sıkıştırılabilirlik özelliği gösterdiği ortaya konmuştur. TMM sonuçları kullanılarak, etkin ortam homojenizasyonu ile bu malzemelerin etkin empedans, kırılma indisi, yoğunluk ve sıkıștırılabilirlik gibi pasif malzeme parametreleri elde edilmiștir. Metamalzemeleri oluşturan metahücrelerin sayısı, geometrik büyüklükleri, dizilim periyodikliği gibi topolojik unsurların iletim kaybı (IK) üzerindeki etkisi incelenerek sözü edilen metamalzemelerin performansları literatüre sunulmuștur. Çalışmaların doğruluğu FEM ile yapılan temel bir karşılaştırma ile gösterilmiştir.

\section{Matematiksel Modellemeler}

\section{1. İç boşluklu bir akustik metamalzemenin transfer matrisi}

Düzlemsel dalga yaklaşımı üzerine geliştirilen transfer matris metodunda (TMM), akustik yapı kendini oluşturan basit alt sisteme ayrıştırılır ve her alt sistem bir transfer matris ile ifade edilerek alt sistemin uçları arasında ses basıncı ve parçacık hızlarına bağlı dört kutup parametreleri elde edilir. Daha sonra bu transfer matrisleri bir araya getirilerek tüm sistemin transfer matrisi elde edilir.

Bu çalışmada ele alınan küresel bir iç boşluklu n adet metahücreden oluşmuş (Şekil 1) bir metahücre dizisi için tüm sistem transfer matrisi şu şekilde yazılabilir:

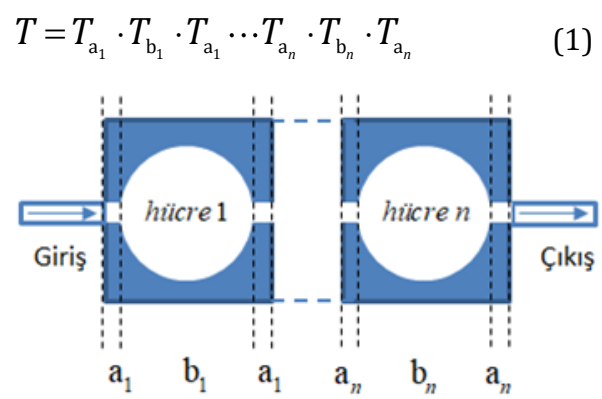

Şekil 1. $n$ adet metahücreden oluşan bir metahücre dizisi

"a" ile gösterilen bölümde bulunan içerisinde akışın olmadığı $l$ boyunda homojen bir düz borunun ve $\mathrm{b}$ ile gösterilen bölümde bulunan $\mathrm{V}$ hacminde küresel bir iç boşluğun viskoz-termal etkilerin ihmal edildiği transfer matrisi sırasıyla [24]: 
DEU FMD 21(62), 449-459, 2019

$$
\begin{aligned}
& T_{\mathrm{a}}=\left[\begin{array}{ll}
T_{11} & T_{12} \\
T_{21} & T_{22}
\end{array}\right]_{\mathrm{a}}=\left[\begin{array}{cc}
\cos k_{0} n_{0} l_{\mathrm{a}} & \mathrm{jZ} \mathrm{Z}_{0} \sin k_{0} n_{0} l_{\mathrm{a}} \\
\frac{\mathrm{j}}{Z_{0}} \sin k_{0} n_{0} l_{\mathrm{a}} & \cos k_{0} n_{0} l_{\mathrm{a}}
\end{array}\right], \\
& T_{\mathrm{b}}=\left[\begin{array}{ll}
T_{11} & T_{12} \\
T_{21} & T_{22}
\end{array}\right]_{\mathrm{b}}=\left[\begin{array}{cc}
1 & 1 \\
1 / Z_{\mathrm{b}} & 1
\end{array}\right]
\end{aligned}
$$

olarak verilir. Burada $k_{0}=\omega / c_{0}$ havada yayınan sesin dalgasayısı ( $\omega$ : yayınan sesin frekansı, $c_{0}$ : ses hızı), $n_{0}=1$ havanın kırılma indisi, $l$ borunun boyu, $Z_{0}=\rho_{0} c_{0} / S\left(\mathrm{~kg} / \mathrm{m}^{4} \mathrm{~s}\right)$ boru içindeki havanın karakteristik empedansı ( $\rho_{0}$ : kütle yoğunluğu, $S$ : giriş ve çıkış boru kesit yüzey alanı), j= $\sqrt{-1}$ ve $Z_{b}=\rho_{0} c_{0} /\left(\mathrm{j} k_{0} \mathrm{~V}\right)$ ise iç boşluğun akustik empedansıdır.

\subsection{Etkin ortam homojenizasyonu}

Literatürde Nicolson-Ross-Weir (NRW) Modeli [25, 26], Saçılma parametre modelleri [27-29] vb. gibi çeşitli etkin ortam homojenizasyonu ile etkin parametre elde etme teknikleri vardır. Ancak bu tekniklerin bazıları rezonans bölgelerinde bașarılı sonuç verememekte, bazıları ise metamalzeme karmaşıklığı arttıkça başarısızlığa uğramaktadır. Bu çalışmada, tüm bu parametre elde etme teknikleri denenmiş ve ele alınan metamalzemeler için en başarılı olduğu düșünülen NRW $[25,26]$ ve KramerKronig integraline dayalı bir teknik [27] kombine edilmiş ve transfer matrisine dayalı olarak yeniden düzenlenerek kullanılmıștır. Bu amaçla etkin akustik empedans, etkin kırılma indisi, etkin yoğunluk ve etkin sıkıștırılabilirlik parametreleri, transfer matris elemanları kullanılarak, etkin pasif ortam homojenizasyonu ile elde edilmiștir. Etkin ortam teorisine göre, Şekil 2.a'da şematik olarak gösterilen herhangi bir akustik metamalzemenin periyodik veya düzensiz dizilimde olup olmamasına bakılmaksızın tüm sistem transfer matrisi ile Şekil 2.b'de görülen bir pasif, homojen malzemenin transfer matrisi eşleştirilir.

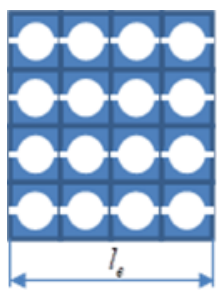

a)

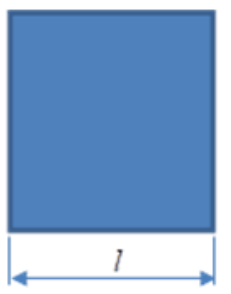

b)
Şekil 2. a) Bir şematik metamalzeme gösterimi, b) Bir homojen pasif malzeme gösterimi

$\mathrm{Bu}$ bağlamda bir metamalzemenin transfer matrisi, tek boyutlu bir homojen akustik ortam için Denklem (2)'de verilen transfer matrisine benzer formda ancak etkin parametreler cinsinden şu şekilde yazılabilir [24];

$$
T_{e}=\left[\begin{array}{cc}
{ }^{e} T_{11} & { }^{e} T_{12} \\
{ }^{e} T_{21} & { }^{e} T_{22}
\end{array}\right]=\left[\begin{array}{lc}
\cos k_{e} n_{e} l_{e} & \mathrm{j} \mathrm{Z}_{e} \sin k_{e} n_{e} l_{e} \\
\frac{\mathrm{j}}{Z_{e}} \sin k_{e} n_{e} l_{e} & \cos k_{e} n_{e} l_{e}
\end{array}\right]
$$

Burada alt indis $e$ etkin parametre anlamında kullanılmaktadır. Homojenize edilmiş metamalzemenin iletim $(t)$ ve yansıma katsayısı (r) sırasıyla şu şekilde hesaplanabilir [24]:

$$
\begin{gathered}
t_{e}=\frac{2}{{ }^{e} T_{11}+\frac{{ }^{e} T_{12}}{Z_{0}}+{ }^{e} T_{21} Z_{0}+{ }^{e} T_{22}} \\
r_{e}=\frac{{ }^{e} T_{11}+\frac{{ }^{e} T_{12}}{Z_{0}}-{ }^{e} T_{21} Z_{0}-{ }^{e} T_{22}}{{ }^{e} T_{11}+\frac{{ }^{e} T_{12}}{Z_{0}}+{ }^{e} T_{21} Z_{0}+{ }^{e} T_{22}}
\end{gathered}
$$

Kompleks etkin empedans ve kompleks etkin kırılma indisi sırasıyla aşağıdaki gibi elde edilebilir;

$$
\begin{aligned}
& Z_{e}=Z_{0} S\left(\frac{1-r_{e}}{1+r_{e}}\right)\left(\frac{\mathrm{kg}}{\mathrm{m}^{2} \mathrm{~s}}\right), \\
& n_{e}=\frac{1}{k_{e} l_{e}} \cos ^{-1}\left({ }^{e} T_{11}\right) .
\end{aligned}
$$

Etkin empedans ve etkin kırılma indisi kullanılarak etkin kütle yoğunluğu ve etkin sıkıştırılabilirlik sırasıyla şu şekilde hesaplanabilir; 


$$
\begin{aligned}
& \rho_{e}=\frac{n_{e}}{c_{0}} Z_{e}\left(\frac{\mathrm{kg}}{\mathrm{m}^{3}}\right), \\
& B_{e}=\frac{n_{e}}{c_{0} Z_{e}}\left(\frac{1}{\mathrm{MPa}}\right) .
\end{aligned}
$$

Burada $B_{e} \quad$ Bulk modülünün tersi olan etkin sıkıștırılabilirliği ifade eder. Etkin yoğunluk ve etkin sıkıştırılabilirliğin negatif değer alması metamalzemenin tipini ve karakterini temsil ettiği için bu parametreler oldukça önemlidir. Ancak bu noktada etkin kırılma indisinin elde edildiği Denklem (8)'in irdelenmesi gerekir. Denklem (7)'de görülen kosinüs fonksiyonunun tek bir çözümü olmadığından, etkin kırılma indisinin gerçel kısmının tek bir değeri yoktur. Bu durum branş (dal) problemi olarak bilinir ve etkin indisin gerçel kısmını belirsiz kılar. Kırılma indisinin sanal kısmı için böyle bir problem yoktur. Bu bağlamda Denklem (8) aşağıdaki gibi yeniden yazılmalıdır;

$$
\begin{aligned}
n_{e}(\mathrm{~m}, \omega) & =\frac{1}{k_{e} l_{e}}\left(\operatorname{real}\left(\cos ^{-1}\left({ }^{e} T_{11}\right)\right)+2 \pi \mathrm{m}\right) \\
& +\frac{\mathrm{j}}{k_{e} l_{e}} \operatorname{imag}\left(\cos ^{-1}\left({ }^{e} T_{11}\right)\right)
\end{aligned}
$$

Burada, real ve imag ișleçleri parantezdeki ifadenin gerçel ve sanal kısımlarını gösterirken, $m$ bir tamsayı olan branş sayısıdır. Eğer metamalzemeler yeterince ince ise $m=0$ değeri yaklaşık çözüm vermektedir. Ancak kesin sonuçlar için frekansa bağlı olarak da değișebilen $\mathrm{m}$ sayıları hesaplanmalıdır. $\mathrm{Bu}$ amaçla Kramers-Kronig ilişkisi ile kırılma indisinin gerçel kısmı sanal kısım yardımıyla hesaplanabilir [27]:

$n_{K-K}\left(\omega_{i}\right)=1+\frac{2}{\pi} \wp\left(\int_{0}^{\infty} \frac{\omega_{i+1} \cdot \operatorname{imag}\left(n_{e}\left(0, \omega_{i+1}\right)\right)}{\omega_{i+1}^{2}-\omega_{i}} d \omega\right)$

Burada, $i$ yeterince sık frekans aralıklarıyla oluşturulan $\omega$ frekans dizisinin indisi, $n_{K-K}(\omega(i))$ i. frekanstaki Kramer-Kronig kırılma indisini ve $\wp$ integralin birincil değerini ifade eder. Denklem (12) kullanılarak branş sayısı şu şekilde elde edilir [27]:

$$
\mathrm{m}_{i}=\operatorname{round}\left[\left(n_{K-K}\left(\omega_{i}\right)-\operatorname{real}\left(n_{e}\left(0, \omega_{i}\right)\right)\right)\right]
$$

Burada round işleci parantezdeki ifadeyi tam sayıya yuvarlar. Burada önemli olan bir diğer durum ise elde edilen parametrelerin fiziksel olarak gerçekçi olup olmadığının tespit edilebilmesidir. $\mathrm{Bu}$ bağlamda, homojenize edilen metamalzemenin pasif bir malzeme olduğu kabulünden gerçel etkin empedansın ve sanal kırılma indisinin pozitif olması ( $\operatorname{real}\left(Z_{e}\right)>0$ ve $\operatorname{imag}\left(n_{e}\right)>0$ ) sağlanmalıdır.

\section{Sayısal Modellemeler ve Analizler}

$\mathrm{Bu}$ bölümde iç boșluklu metahücrelerin homojenizasyonu ve farklı büyüklük ve farklı dizilimlerle elde edilen metahücre dizilerinin iletim kayıpları TMM yöntemi ile elde edilecektir. Şekil 3.a'da bir meta hücre çeşitli görünüşleri ile birlikte, Şekil 3.b'de 3 adet metahücreden olușan bir metahücre dizisi verilirken Şekil 3.c'de çok sayıda metahücre dizilerinden elde edilen bir panel akustik metamalzemenin katı modeli sunulmuştur. Sözü edilen analizlere geçmeden TMM'nin metamalzemelerin iletim kayıplarının elde edilmesinde başarılı şekilde kullanılabilirliğinin gösterilmesi önemlidir. İletim kaybı $\mathrm{dB}$ (desibel) cinsinden aşağıdaki şekilde hesaplanmıştır:

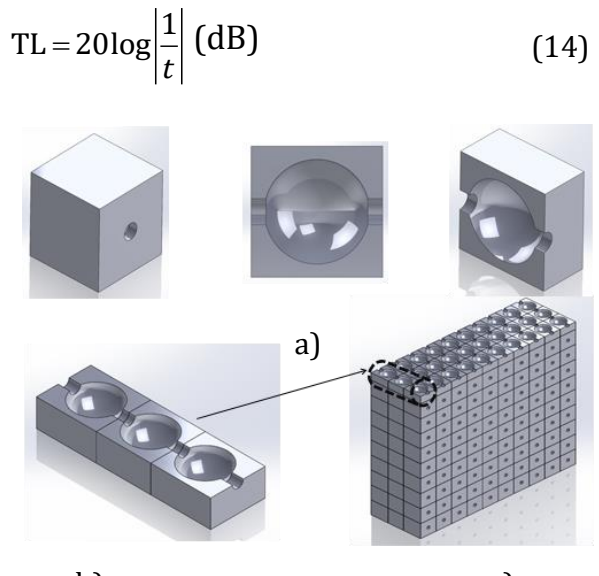

b)

c)

Şekil 3. a) Bir iç boşluklu kübik metahücre ve kesilmiș görüntüleri b) 3 metahücre ile elde edilen bir metahücre dizisi c) Çok sayıda metahücre dizilerinden elde edilen bir panel metamalzeme 


\subsection{Doğrulama çalışması}

Bu bölümde TMM'nin doğrulanması için, Sekil 4.a'da görüldüğü gibi $80 \mathrm{~mm}$ uzunluğunda, 5 mm yarıçapında bir boru üzerine eşit aralıklarla yerleștirilmiş üç adet $10 \mathrm{~mm}$ yarıçapında küresel iç boşluktan oluşturulan bir metahücre dizisi ele alınmıștır. Bu dizinin iletim katsayısı TMM yöntemi ve Comsol ${ }^{\circledR}$ programı yardımıyla Sonlu Elemanlar Yöntemi (SEM) ile elde edilmiștir. SEM modelinde, boyutları 1.44-8 mm arasında değișen 4068 adet tetrahedral ve 1212 adet üçgen eleman kullanılmıştır. Kullanılan eleman sayısı ve tipi Comsol@ "fine mesh" özelliğiyle otomatik olarak yakınsama kontrolü yapılarak belirlenmiștir. Analizlerde lineer elastik akışkan eleman seçilmiștir. Şekil 4.b'de metahücrenin ağ örgüsü (mesh) görülmektedir. Çalışmada giriş ve çıkış uçlarına düzlemsel dalga teorisine göre [24] sınır koşulları uygulanmış ve giriş ucuna (sol uç) $\left|P_{\text {giris }}\right|=1 \mathrm{~Pa}$ şiddetinde bir tek boyutlu harmonik ses dalgası gönderilmiștir. $\mathrm{Bu}$ gelen dalgaya bağlı olarak çıkış borusu uç yüzeyindeki ortalama ses basınç düzeyi $\left|P_{\text {cklss }}\right|$ elde edilerek, iletim katsayısı $t, 10$ $\mathrm{Hz}$ adımlarla, 20-8000 $\mathrm{Hz}$ aralığı için $t=\left|P_{\text {sklks }} / P_{\text {giris }}\right|$ olarak hesaplanmıştır. Denklem

(14) ile verilen iletim kaybı TL, sadece iletim katsayısı t'ye bağlı bir değişken olduğundan, Şekil 5'te iletim katsayısı t karşılaştırılmıştır. TMM ile iletim katsayısı Denklem (5) kullanılarak elde edilmiştir.

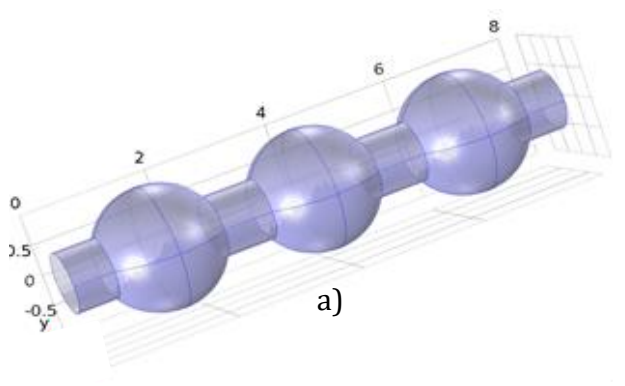

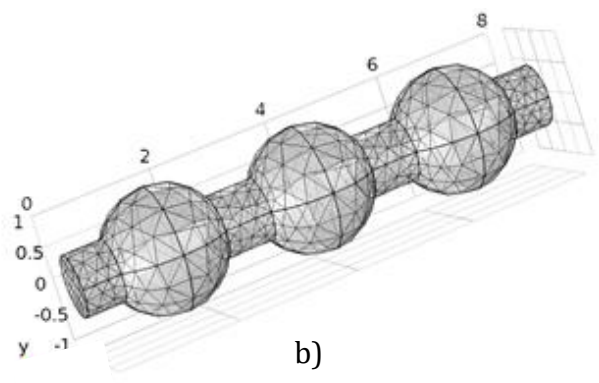

Şekil 4. a) Metahücre dizisinin akustik ortam katı modeli, b) Sonlu elemanlar ağ örgüsü

Şekil 5'te görüldüğü gibi TMM sonuçları ile FEM sonuçları arasında kabul edilebilir düzeylerde bir uyum gözlemlenmektedir. Burada, tam iletimin gerçekleștiği pikler Fabry-Perot (FP) rezonans frekansları olarak bilinir ve periyodik yapılarda yansıyan ve iletilen dalgaların girişimleri nedeniyle ortaya çıkar. Bu rezonans frekanslarının sayısı, yapıdaki periyodik eleman sayısının bir eksiği kadardır. Bu frekanslar TMM ile $1840 \mathrm{~Hz}$ ve $3440 \mathrm{~Hz}$ 'de, FEM ile $1940 \mathrm{~Hz}$ ve $3440 \mathrm{~Hz}$ 'de bulunmuștur. Görüldüğü gibi 1.FP frekansında $100 \mathrm{~Hz}$ 'lik bir sapma gözlenmiştir. Yapılan incelemelerde, malzeme geometrisinde (uzunluk, çap) yapılan küçük değișikliklerin SEM sonuçlarında önemli değişiklikler yaratmadığı ancak TMM ile analitik frekansların küçük miktarlarda sola ya da sağa kayabildiği gözlenmiștir. Dolayısıyla bu sapmanın analitik ifadelere bağlı TMM'nin küçük geometrik farklılıklara karşı duyarlılı̆̆ından çıtığı yorumlanmaktadır. Ancak sonuçlara karakter olarak bakıldığında iki yöntemin oldukça uyumlu olduğu görülmektedir. 


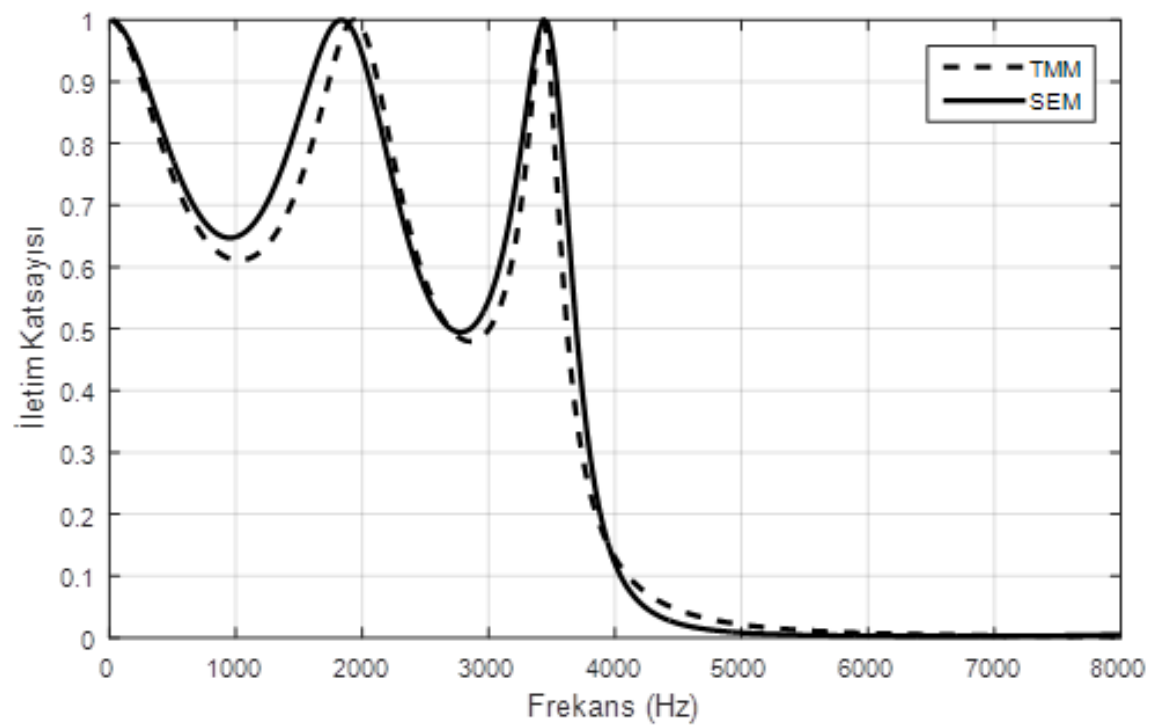

Şekil 5. Transfer matris (TMM) ve Sonlu Elemanlar Metodu (SEM) ile elde edilen iletim katsayısı

\section{2. İç boşluklu akustik metamalzeme tasarımı}

Bu bölümde TMM yöntemi ile Şekil 6'da görülen çeşitli metadizilerin iletim katsayısı üzerindeki etkileri incelenecektir. B harfi ile gösterilen görece büyük küresel boşluğun yarıçapı $15 \mathrm{~mm}$, $\mathrm{K}$ harfi ile gösterilen görece küçük küresel boșluğun yarıçapı 7.5 mm'dir. Küp șeklindeki B ve $\mathrm{K}$ metahücrelerinin bir kenarının uzunluğu, çap düşmesi nedeniyle, sırasıyla yaklaşık $39 \mathrm{~mm}$ ve $24.5 \mathrm{~mm}$ 'dir.

$\mathrm{Bu}$ çalışmalara geçmeden önce elde edilen metahücre dizilerinin gerçekte bir meta davranış sergileyip sergilemediği, sergilediyse ne tip bir davranışa sahip olduğunun tespit edilmesi oldukça önemlidir. Metamalzeme tasarım çalışmalarında etkin parametrelerin elde edilerek bu parametreler üzerinde yapılacak çalışmalarla istenen en yüksek akustik performansa ulaşmak en tercih edilen yoldur.

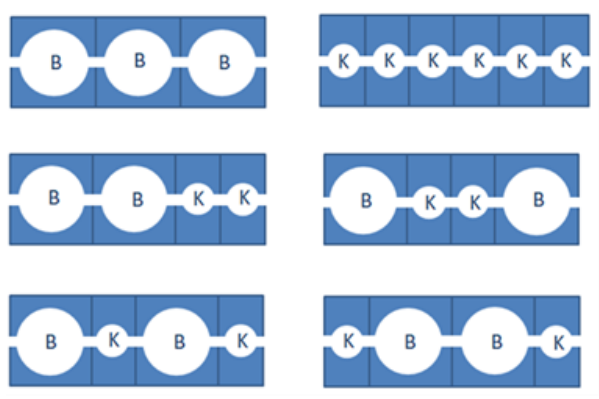

Şekil 6. Farklı dizilimlere sahip metahücre dizileri

\subsubsection{Pasif ortam homojenizasyonu ile etkin parametrelerin elde edilmesi}

$\mathrm{Bu}$ bölümde Şekil 6'da verilen tüm metadizi kombinasyonları için etkin parametreler elde edilmiș ve hepsinin meta davranış sergilediği görülmüștür. Ancak burada sadece Şekil 6'nın birinci satır birinci sütununda görülen $\mathrm{BBB}$ dizilimi için etkin parametreler sunulmuştur (Şekil 7). Etkin parametreler Bölüm 2.2.'de verilen prosedür yardımıyla elde edilmiștir. Parametrelerin başarılı olarak elde edilip edilmediği şu iki husus göz önüne alınarak değerlendirilmelidir $[27,28]$;

1)Pasif malzeme koşulu sağlanmalıdır; yani gerçel etkin empedans ve sanal etkin kırılma indisi her frekansta pozitif olmalıdır.

2)Metamalzeme davranışı gözlemlenmelidir; yani etkin yoğunluk ve/veya etkin sıkıștırılabilirliğin gerçel kısımlarının belirli bölgelerinde sıfır veya negatif davranış gözlenmelidir.

$\mathrm{Bu}$ bağlamda Şekil 7 incelendiğinde homojenizasyonun bașarılı șekilde yapıldı ğı

görülmektedir. Şekil 7.b ile gerçel etkin kırılma indisinin elde edilmesinde ihtiyaç duyulan branş sayısının tüm frekans bölgelerinde sıfır alınarak gerçekleștirildiği homojenizasyonların gerçeği yansıtmayacağı da gösterilmiştir. Bununla birlikte küresel hücrenin ilk kavite 
modu olan $2560 \mathrm{~Hz}$ 'den sonra yaklaşık sıfır yoğunluk ve negatif sıkıştırılabilirliğin elde edilmesi hücrelerin metahücre olarak davrandığını göstermektedir.
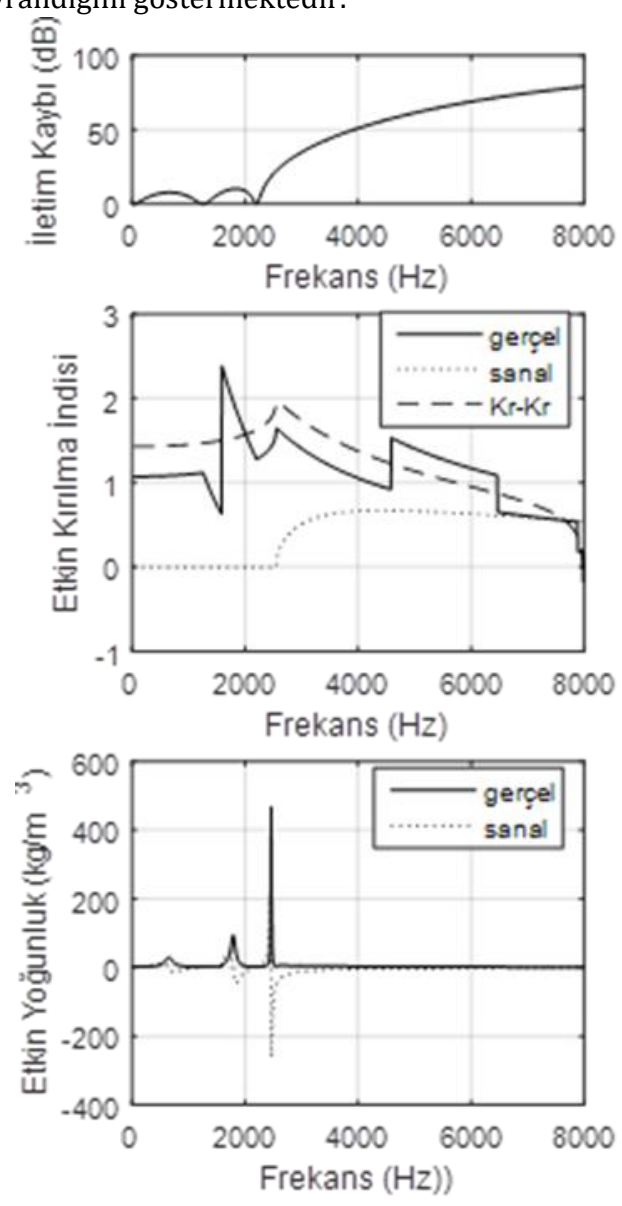
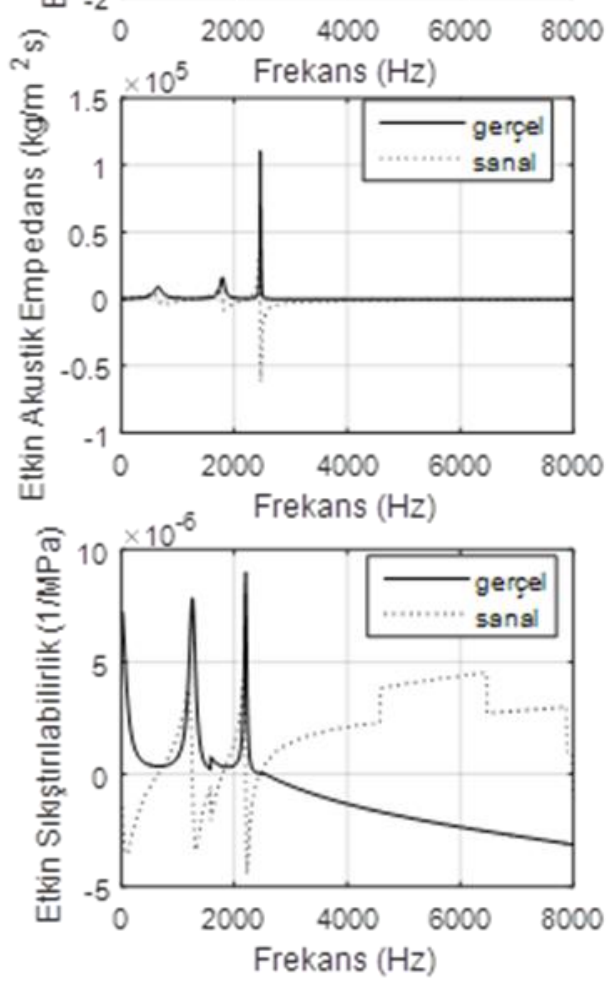

Şekil 7. BBB dizilimi için a) İletim kaybı (TL), b) Branș sayısı, c) Etkin kırılma indisi, d) Etkin akustik empedans, e) Etkin yoğunluk, f) Etkin sıkıștırılabilirlik (Kr-Kr: Kramer Krönig yaklaşımı)
3.2.2. Farklı dizilimlere
sahip metahücrelerin iletim kaybı
gözlenmektedir. Burada ayrıntılarına girilmemekle beraber bu bölgelerin yüksek yutum bölgeleri de olduğu bilinmektedir [30- iletim yarattı̆̆ gösterildikten sonra, Şekil 6'da verilen yaklaşık aynı toplam uzunluğa sahip diğer metahücre dizilimlerinin iletim kaybı üzerindeki etkileri incelenmiș ve Şekil 9'da sunulmuştur. $\mathrm{Bu}$ bölümde öncelikle metahücre sayısının 31 . Özellikle BBB diziliminin hücre kavite artırılmasının TL üzerindeki etkisi modundan $(2560 \mathrm{~Hz})$ başlayarak yüksek ses gösterilecektir. Bu amaçla bir (B), iki (BB) ve üç iletim kaybı elde edebildiği görülmektedir. (BBB) metahücreden oluşan dizilimlerin iletim Çoklu periyodik metahücrelerin daha etkili bir kaybı elde edilerek Şekil 8'de sunulmuştur.
Şekil 8 incelendiğinde yine $B B$ ve $B B B$ dizilimlerinde beklendiği gibi Fabry-Perot (FP) frekansları gözlenmiștir. Burada tam iletimin gerçekleştiği yani iletim kayıplarının sıfır olduğu noktalar FP frekanslarıdır. B ile karşılaştırıldığında, bu FP frekans bölgesinde yüksek iletim kayıpların elde edildiği 


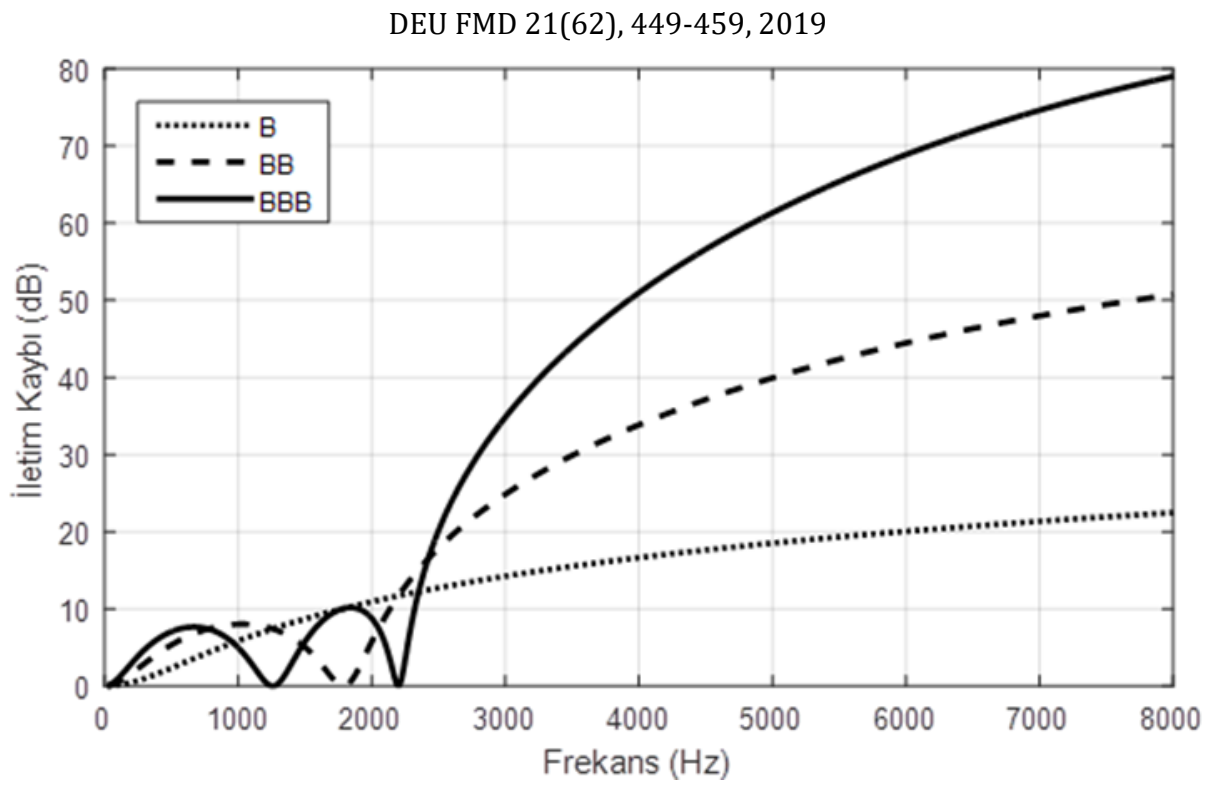

Şekil 8. B, BB ve BBB dizilimlerinin iletim kaybı

Şekil 9 incelendiğinde ilk olarak KKKKKK diziliminin tüm frekans bölgelerinde en düşük TL'e sahip olduğu görülmektedir. Diğer metahücre dizileri malzemenin ses iletiminin azaltılmasının istendiği frekans bölgelerine göre değerlendirilmelidir. $\mathrm{Bu}$ amaçla BKKB diziliminin oldukça geniş bir bantta yaklaşık $1200 \mathrm{~Hz}-2600 \mathrm{~Hz}$ aralığında etkili olduğu, bu bölümden sonra BBB diziliminin en yüksek TL'e sahip olduğu açıktır. 1200 Hz'den önceki bölgede ise amaca göre en uygun dizilim seçilebilir. $\mathrm{Bu}$ çalışmayla yüksek iletim kaybı beklentisine sahip bir metamalzeme seçilirken farklı metahücre kombinasyonlarının incelenmesi gerektiği gösterilmiștir.

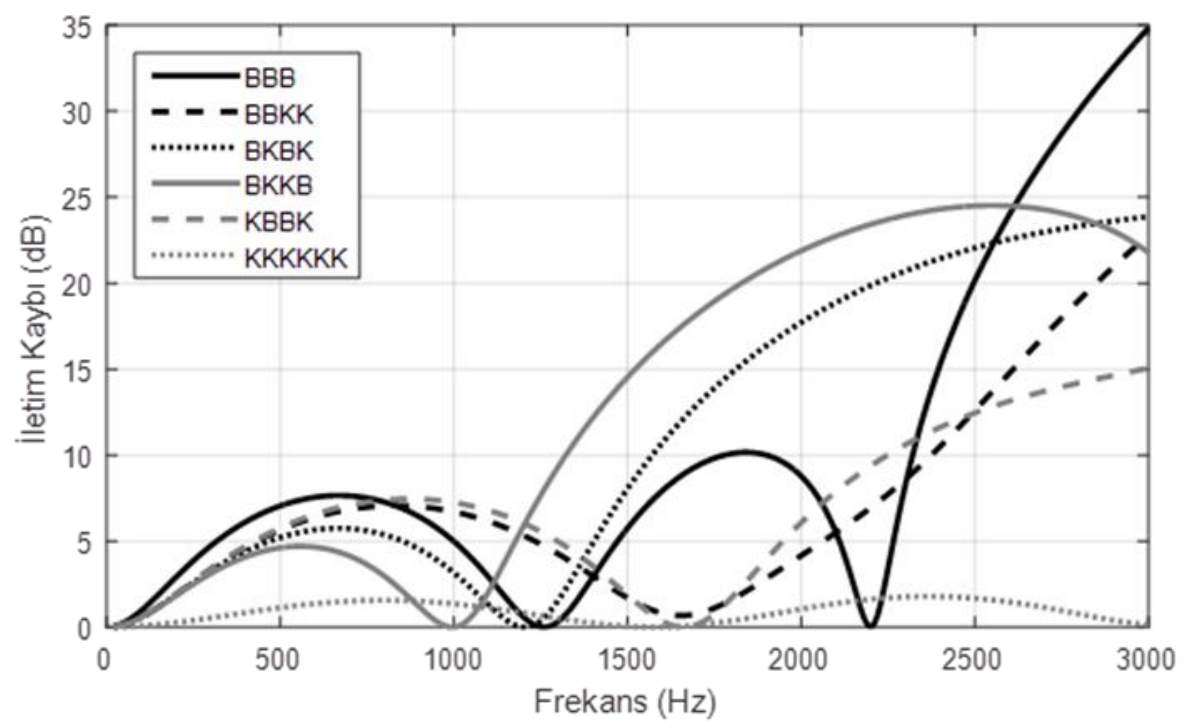

a) 


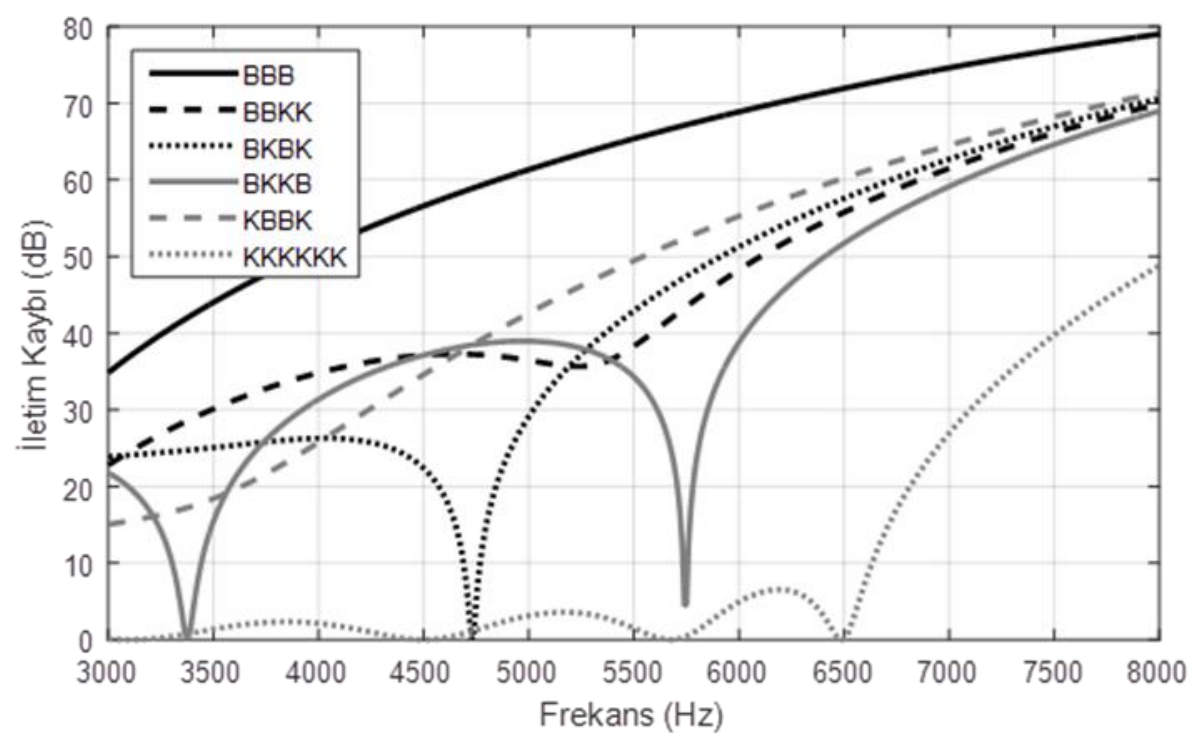

b)

Şekil 9. Çeşitli metahücre dizilerinin iletim kayıpları (TL) a) $20-3000 \mathrm{~Hz}$, b) $3000-8000 \mathrm{~Hz}$

\section{Sonuçlar}

$\mathrm{Bu}$ çalışma ile vizko-termal etkilerin ihmal edildiği küresel iç boşluklu akustik metahücrelerin homojenizasyonu gerçekleştirilerek metamalzemelerin etkin empedans, kırılma indisi, yoğunluk ve sıkıştırılabilirlik gibi etkin ortam parametreleri başarılı şekilde elde edilmiştir. Bununla birlikte, farklı metahücre dizilimlerinin iletim kaybı üzerindeki etkileri incelenmiștir. Çalıșmada transfer matris metodu (TMM) kullanılmış ve TMM'nin doğruluğu sonlu elemanlar yöntemi ile yapılan karșılaștırma ile gösterilmiștir. Çalıșma sonuçları irdelendiğinde metamalzemeleri olușturan metahücrelerin sayısı, geometrik büyüklükleri, dizilim periyodikliği gibi unsurların malzemelerin iletim kaybı (TL) performansı üzerinde etkili olduğu gösterilmiştir. $\mathrm{Bu}$ çalışmada, pek çok ana malzemenin uygun şekilde küresel boşluklu olarak tasarlanması ile bir metamalzemenin yaratılabileceği ve sonucunda herhangi bir ek pasif yalıtım malzemesi kullanılmadan oldukça iyi bir yalıtım malzemesi elde edilebileceği sayısal analizlerle gösterilmiștir. $\mathrm{Bu}$ tip metamalzemelerin visko-termal yutum özelliklerinin belirlenmesi ve gerekirse bu özelliklerin iyileștirilmesi ile aynı malzemelerin iyi birer ses yutucu malzeme olarak da tasarlanması bu çalıșmanın bir sonraki adımı olacaktır.

\section{Kaynaklar}

[1] Veselago, V. G. 1968. The electrodynamics of substances with simultaneously negative values of $\mu$ and $\varepsilon$, Soviet Physics Uspekhi, 10, 4, 509-514. DOI:10.1070/PU1968v010n04ABEH003699

[2] Ambati, M., Fang, N., Sun, C., Zhang, X. 2007. Surface resonant states and superlensing in acoustic metamaterials, Physical Review B, 75(19), 195447. DOI: 10.1103/PhysRevB.75.195447

[3] Guenneau, S., Movchan, A., Pétursson, G., Ramakrishna, S. A. 2007. Acoustic metamaterials for sound focusing and confinement, New Journal of physics, 9(11), $399 . \quad$ DOI: $10.1088 / 1367-$ 2630/9/11/399

[4] Popa, B. I., Zigoneanu, L., Cummer, S. A. 2011. Experimental acoustic ground cloak in air, Physical review letters, 106(25), 253901. DOI:10.1103/PhysRevLett.106.253901

[5] Cheng, Y., Yang, F., Xu, J. Y., Liu, X. J. 2008. A multilayer structured acoustic cloak with homogeneous isotropic materials, Applied Physics Letters, 92(15), 151913. DOI: 10.1063/1.2903500

[6] Cummer, S. A., Popa, B. I., Schurig, D., Smith, D. R., Pendry, J., Rahm, M., Starr, A. 2008. Scattering theory derivation of a 3D acoustic cloaking Shell, Physical review letters, 100(2), 024301. DOI: 10.1103/PhysRevLett.100.024301

[7] Farhat, M., Guenneau, S., Enoch, S., Movchan, A. B. 2009. Cloaking bending waves propagating in thin 


\section{DEU FMD 21(62), 449-459, 2019}

elastic plates, Physical Review B, 79(3), 033102. DOI: $10.1103 /$ PhysRevB.79.033102

[8] Zhang, X., Liu, Z. 2004. Negative refraction of acoustic waves in two-dimensional phononic crystals, Applied Physics Letters, 85(2), 341-343. DOI: $10.1063 / 1.1772854$

[9] Liu, Z., Zhang, X., Mao, Y., Zhu, Y. Y., Yang, Z., Chan, C. T., Sheng, P. 2000. Locally resonant sonic materials, Science, 289(5485), 1734-1736. DOI: 10.1126/science.289.5485.1734

[10] Zhao, H., Liu, Y., Wang, G., Wen, J., Yu, D., Han, X., Wen, X. 2005. Resonance modes and gap formation in a two-dimensional solid phononic crystal, Physical Review B, 72(1), 012301. DOI: 10.1103/PhysRevB.72.012301

[11] Fang, N., Xi, D., Xu, J., Ambati, M., Srituravanich, W., Sun, C., Zhang, X. 2006. Ultrasonic metamaterials with negative modulus, Nature materials, 5(6), 452456. DOI: $10.1038 / \mathrm{nmat} 1644$

[12] Hu, X., Ho, K. M., Chan, C. T., Zi, J. 2008 Homogenization of acoustic metamaterials of Helmholtz resonators in fluid, Physical Review B, 77(17), $172301 . \quad$ DOI: 10.1103/PhysRevB.77.172301

[13] Lee, S. H., Park, C. M., Seo, Y. M., Wang, Z. G., Kim, C. K. 2009. Acoustic metamaterial with negative modulus, Journal of Physics: Condensed Matter, $21(17), \quad 175704 . \quad$ DOI: $10.1088 / 0953$ $8984 / 21 / 17 / 175704$

[14] Lee, S. H., Park, C. M., Seo, Y. M., Wang, Z. G., Kim, C. K. 2009. Acoustic metamaterial with negative density, Physics letters A, 373(48), 4464-4469. DOI 10.1016/j.physleta.2009.10.013

[15] Yang, Z., Mei, J., Yang, M., Chan, N. H., Sheng, P. 2008. Membrane-type acoustic metamaterial with negative dynamic mass, Physical review letters, 101(20), 204301. 10.1103/PhysRevLett.101.204301

[16] Yao, S., Zhou, X., Hu, G. 2008. Experimental study on negative effective mass in a $1 \mathrm{D}$ mass-spring system New Journal of Physics, 10(4), 043020. DOI: $10.1088 / 136-2630 / 10 / 4 / 043020$

[17] Croënne, C., Lee, E. J. S., Hu, H., Page, J. H. 2011. Band gaps in phononic crystals: Generation mechanisms and interaction effects, AIP Advances, 1(4), 041401. DOI: $10.1063 / 1.3675797$

[18] Chen, Y., Wang, L. 2014. Periodic co-continuous acoustic metamaterials with overlapping locally resonant and Bragg band gaps, Applied Physics Letters, 105(19), 191907. DOI: 10.1063/1.4902129

[19] Krushynska, A. O., Miniaci, M., Bosia, F., Pugno, N. M. 2017. Coupling local resonance with Bragg band gaps in single-phase mechanical metamaterials, Extreme Mechanics Letters, 12, 30-36. DOI: 10.1016/j.eml.2016.10.004

[20] Li, J., Chan, C. T. 2004. Double-negative acoustic metamaterial, Physical Review E, 70(5), 055602. DOI: $10.1103 /$ PhysRevE.70.055602
[21] Ding, Y., Liu, Z., Qiu, C., Shi, J. 2007. Metamaterial with simultaneously negative bulk modulus and mass density, Physical review letters, 99(9), 093904. DOI: 10.1103/PhysRevLett.99.093904

[22] Cheng, Y., Xu, J. Y., Liu, X. J. 2008. One-dimensional structured ultrasonic metamaterials with simultaneously negative dynamic density and modulus, Physical Review B, 77(4), 045134. DOI: 10.1103/PhysRevB.77.045134

[23] Bongard, F., Lissek, H., Mosig, J. R. 2010. Acoustic transmission line metamaterial with negative/zero/positive refractive index, physical $\begin{array}{llll}\text { Review B, 82(9), } 094306 . \quad \text { DOI: } & \end{array}$ 10.1103/PhysRevB.82.094306

[24] Munjal, M.L. 1987. Acoustics of ducts and mufflers with applications to exhaust and ventilation system design, Wiley Interscience Publication, Bangolore.

[25] A.M. Nicolson, G. Ross. 1970. Measurement of intrinsic properties of materials by time domain technique, IEEE Transactions on Instrumentation and Measurement, 19 (11) 377-382. DOI: 10.1109/TIM.1970.4313932

[26] W.B. Weir. 1974. Automatic measurement of complex dielectric constant and permeability at microwave frequencies, Proceedings of the IEEE, 62(1), 33-36. DOI: 10.1109/PROC.1974.9382

[27] Szabo, Zs, Park G, Hedge R, Li E. 2010. A unique extraction of metamaterial parameters based on Kramers-Kronig relationship, IEEE Trans Microwave Theory and Technology, 58(10) 26462653. DOI: $10.1109 /$ TMTT.2010.2065310

[28] Fokin, V., Ambati, M., Sun, C., Zhang, X. 2007. Method for retrieving effective properties of locally resonant acoustic metamaterials, Physical review B, 76(14), 144302 10.1103/PhysRevB.76.144302

[29] Chen, X., Grzegorczyk, T. M., Wu, B. I., Pacheco Jr, J., Kong, J. A. 2004. Robust method to retrieve the constitutive effective parameters of metamaterials, Physical Review E, 70(1), 016608. DOI: 10.1103/PhysRevE.70.016608

[30] Theocharis G., Richoux O. Romero G.V., Merkel A, Tournat V. 2014. Limits of slow sound propagation and transparency in lossy, locally resonant periodic structures, New Journal of Physics, 16, 093017. DOI: $10.1088 / 1367-2630 / 16 / 9 / 093017$

[31] Molerón M., Serra-Garcia M., Daraio C. 2016. Viscothermal effects in acoustic metamaterials: from total transmission to total reflection and high absorption, New Journal of Physics, 18, 033003. DOI: $10.1088 / 1367-2630 / 18 / 3 / 033003$. 